\title{
Cold- and overfeeding-induced changes in the human skeletal muscle proteome.
}

Citation for published version (APA):

Wijers, S. L., Smit, E., Saris, W. H. M., Mariman, E. C. M., \& van Marken Lichtenbelt, W. D. (2010). Coldand overfeeding-induced changes in the human skeletal muscle proteome. Journal of Proteome Research, 9(5), 2226-2235. https://doi.org/10.1021/pr9010074

Document status and date:

Published: 01/01/2010

DOI:

10.1021/pr9010074

Document Version:

Publisher's PDF, also known as Version of record

Document license:

Taverne

Please check the document version of this publication:

- A submitted manuscript is the version of the article upon submission and before peer-review. There can be important differences between the submitted version and the official published version of record.

People interested in the research are advised to contact the author for the final version of the publication, or visit the DOI to the publisher's website.

- The final author version and the galley proof are versions of the publication after peer review.

- The final published version features the final layout of the paper including the volume, issue and page numbers.

Link to publication

\footnotetext{
General rights rights.

- You may freely distribute the URL identifying the publication in the public portal. please follow below link for the End User Agreement:

www.umlib.nl/taverne-license

Take down policy

If you believe that this document breaches copyright please contact us at:

repository@maastrichtuniversity.nl

providing details and we will investigate your claim.
}

Copyright and moral rights for the publications made accessible in the public portal are retained by the authors and/or other copyright owners and it is a condition of accessing publications that users recognise and abide by the legal requirements associated with these

- Users may download and print one copy of any publication from the public portal for the purpose of private study or research.

- You may not further distribute the material or use it for any profit-making activity or commercial gain

If the publication is distributed under the terms of Article $25 \mathrm{fa}$ of the Dutch Copyright Act, indicated by the "Taverne" license above, 


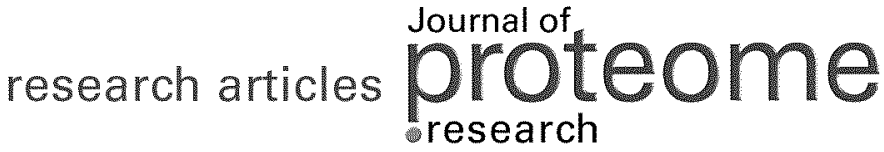

\section{Cold- and Overfeeding-induced Changes in the Human Skeletal Muscle Proteome}

\author{
Sander L. J. Wijers, ${ }^{*}$ Egbert Smit, Wim H. M. Saris, Edwin C. M. Mariman, and \\ Wouter D. van Marken Lichtenbelt \\ Department of Human Biology, Nutrition and Toxicology Research Institute Maastricht (NUTRIM),
Maastricht University, PO Box 616, 6200 MD Maastricht, The Netherlands
}

Received November 5, 2009

\begin{abstract}
Adaptive thermogenesis, the increase in energy expenditure in response to diet or cold exposure, shows large interindividual differences. The objective of this study was to investigate the proteins in human muscle tissue that relate to this variation. Therefore, we studied correlations between changes in expressions of proteins and increases in energy expenditure. This, in proteomic research, innovative application of widely used statistical approaches optimized the information yield in this study. The metabolic responses to cold and overfeeding in 9 lean adult male subjects were measured in a respiration chamber in a baseline condition, during three days of cold exposure and during three days of overfeeding. After each respiration chamber measurement a muscle biopsy was taken, from which proteins were isolated and separated using 2D gel-electrophoresis. Ninety-five spots that were significantly changed were analyzed using MALDI-TOF/TOF mass spectrometry. Of these proteins, 52 have been identified. Remarkably, many of the identified proteins that changed in expression significantly after overfeeding and after cold exposure are part of the glycolytic pathway. However, the identified proteins are not considered to be rate limiting. After overfeeding, the abundance of these glycolytic proteins increased. Upon cold exposure, differences in glycolytic protein concentrations related significantly to the interindividual differences in cold-induced adaptive thermogenesis. Moreover, increased abundance of ATP synthase subunits suggested an increased ATP-production. This shows that upon cold exposure ATP utilizing processes might be involved that were not apparent in the baseline situation. The results of this study stress the importance of changes in glycolytic proteins in both coldand overfeeding-induced adaptive thermogenesis.
\end{abstract}

Keywords: adaptive thermogenesis • nonshivering thermogenesis • proteomics • MALDI-TOF/TOF

\section{Introduction}

Adaptive thermogenesis is the increase of energy expenditure upon cold exposure or dietary changes. ${ }^{1}$ Early studies in rodents showed 2- to 4 -fold increases in energy expenditure after cold exposure, without any shivering occurring. ${ }^{2}$ After overfeeding, similar studies showed 2-fold increases in energy expenditure. ${ }^{3}$ In humans, average energy expenditure increases modestly $(\sim 5 \%)$ after overfeeding and mild cold exposure. ${ }^{4-6}$ However, interindividual differences are substantial. Total daily energy expenditure (TDEE) increases maximally up to $15 \%$ in some individuals, while others do not show increased energy expenditure at all. ${ }^{4-6}$ These differences between individuals might explain interindividual differences in the development of obesity, since small differences in energy expenditure can lead to long-term weight gain or weight loss. ${ }^{7}$ Although the mechanisms behind adaptive thermogenesis have been studied extensively in rodents, in humans they have not yet been elucidated.

* To whom correspondence should be addressed. Phone: +31433884260 Fax: +31433670976. E-mail: S.Wijers@hb.unimaas.nl.
We have recently shown that energy expenditure increases both upon mild cold exposure and after overfeeding and that the individual changes in energy expenditure after cold exposure were correlated to those after overfeeding. ${ }^{6}$ Changes in energy expenditure in both situations were related to changes in plasma norepinephrine concentrations. Therefore, it is likely that similar underlying mechanisms play a role, regulated by the sympathetic nervous system. In rodents it has been shown that the increases in energy expenditure after cold exposure and overfeeding are mainly due to mitochondrial uncoupling via uncoupling protein 1 (UCP-1) in brown adipose tissue (BAT), regulated by the sympathetic nervous system. ${ }^{8}$ However, BAT has long been neglected in humans, but recent studies indicate that BAT is important in adult humans too. ${ }^{9,10}$ Furthermore, in humans, it has been shown that skeletal muscle tissue accounts for $40-50 \%$ of sympathomimeticinduced thermogenesis. ${ }^{11,12}$ Moreover, skeletal muscle mitochondrial uncoupling changes upon mild cold exposure are correlated to increases in energy expenditure. ${ }^{13}$

Because hardly any UCP-1 is expressed in skeletal muscle tissue, other proteins or mechanisms have to be responsible for the increase in energy expenditure. From the known UCP-1 
Table 1. Subject Characteristics

\begin{tabular}{lll}
\hline & mean & SEM \\
\hline Age $(\mathrm{yr})$ & 23.67 & 2.38 \\
Height $(\mathrm{m})$ & 1.85 & 0.03 \\
Weight $(\mathrm{kg})$ & 76.90 & 3.31 \\
Body mass index $\left(\mathrm{kg} / \mathrm{m}^{2}\right)$ & 22.54 & 3.12 \\
Body fat $(\%)$ & 15.74 & 1.79 \\
Fat free mass $(\mathrm{kg})$ & 64.53 & 2.08
\end{tabular}

homologues, only UCP-3 is present in skeletal muscle tissue in adequate amounts. However, cold exposure or overfeeding do not show increases in UCP-3 protein or mRNA expression, ${ }^{13,14}$ indicating that the main function of UCP-3 is not the regulation of adaptive thermogenesis.

Because the exact mechanisms of skeletal muscle adaptive thermogenesis are unknown, proteomic research is a suitable tool to look for alternative proteins involved in adaptive thermogenesis. Therefore, we have compared the changes in the skeletal muscle (vastus lateralis) proteome of human subjects in three situations: in a baseline condition and after exposure to mild cold or overfeeding. Since interindividual differences in adaptive thermogenesis are large, these personal characteristics have to be taken into account in analyzing data. Therefore, correlations between changes in expressions of proteins and increase in energy expenditure have been made to explain the interindividual variability. This, in proteomics research, innovative application of widely used statistical methods optimized information yield in this study. We hypothesized that the same proteins are involved in both coldand diet-induced adaptive thermogenesis and that changes in the abundance of these proteins are similar in size and direction.

\section{Materials and Methods}

2.1. Subjects. Thirteen healthy male Caucasian volunteers participated in the study described previously. ${ }^{6}$ A subpopulation of this study was used for this proteomic approach. We obtained muscle biopsies in three interventions (baseline, overfeeding, and mild cold exposure) ( $n=9$ for each condition). Subject characteristics are shown in Table 1. All subjects signed an informed consent for the study protocol, which was approved by the Institutional Review Board of Maastricht University.

2.2. Experimental Protocol. Subjects stayed in a respiration chamber, ${ }^{15}$ twice for $36 \mathrm{~h}$, once for $84 \mathrm{~h}$. The baseline condition consisted of $36 \mathrm{~h}$ at $22{ }^{\circ} \mathrm{C}$ in energy balance. The overfeeding condition consisted of 3 days of overfeeding with a diet of $160 \%$ energy balance, of which the last $36 \mathrm{~h}$ was at $22{ }^{\circ} \mathrm{C}$ in the respiration chamber. The mild cold exposure consisted of $84 \mathrm{~h}$ at $16{ }^{\circ} \mathrm{C}$ in energy balance. All subjects started with the baseline situation. Thereafter, the order of the overfeeding and mild cold intervention was randomly assigned.

The temperature of the mild cold situation $\left(16{ }^{\circ} \mathrm{C}\right)$ in this study setting has been validated previously. ${ }^{16}$ No shivering occurred in the study by van Ooijen et al, ${ }^{16}$ as was verified with electromyography (EMG). Nevertheless, in the present study, each participant had to fill out an hourly questionnaire whether shivering occurred (none of the subjects reported any occurrence of shivering).

Energy balance was based on individually calculated energy requirements: after measurement of sleeping metabolic rate (SMR) during the first night in the respiration chamber, an estimated total daily energy expenditure (TDEE) was calculated by multiplying SMR with a physical activity index (PAI) of 1.6. ${ }^{17}$ This PAI is a small overestimation of the real PAI to prevent occurrence of a negative energy balance, that is, semistarvation, which would be a confounding factor when compared to the overfeeding intervention. Energy intake was adjusted accordingly. Macronutrient composition of all meals was 47:38:15\% energy from carbohydrate, fat, and protein, respectively.

During overfeeding, subjects received a diet containing $160 \%$ of the energy required for energy balance, two days before and during their stay in the respiration chamber. The PAI of the free-living situation was estimated after questioning the subject: for each hour of moderate physical activity per day, the PAI was increased with 0.2 above the standard 1.6 for sedentary subjects. The SMR of the baseline situation was used as a base for this calculation.

Subjects entered the respiration chamber at $20.00 \mathrm{~h}$ and were allowed to acclimate overnight. All subjects wore identical sets of clothing throughout the study and a standard daily activity protocol was applied, ${ }^{18}$ describing all activities required by the subjects. The subjects measured their own body weight each morning on a digital balance, accurate to the nearest $0.1 \mathrm{~kg}$, in fasted state and after voiding.

Immediately upon leaving the respiration chamber after each intervention, a percutaneous muscle biopsy was taken, from M. vastus lateralis according to the technique of Bergström. ${ }^{19}$ The biopsy was quickly frozen in liquid nitrogen and stored at $-80{ }^{\circ} \mathrm{C}$ for subsequent analyses.

2.2.1. Energy Expenditure. The respiration chamber is a 14 $\mathrm{m}^{3}$ room, furnished with a bed, chair, television, radio, telephone, computer, washbowl and deep freeze toilet. Air locks provide passage for exchange of food and urine. Energy expenditure was determined from the subjects' $\mathrm{O}_{2}$ consumption, $\mathrm{CO}_{2}$ production and urine nitrogen excretion according to the Weir equation. ${ }^{20}$ The respiration chamber was ventilated with fresh air at a rate of $70-80 \mathrm{~L} / \mathrm{min}$. A dry gas meter (G4 Schlumberger) measured the ventilation rate. A paramagnetic $\mathrm{O}_{2}$ analyzer (OA 184A, Servomex) and an infrared $\mathrm{CO}_{2}$ analyzer (Uras 3G, Hartmann and Braun) were used to analyze the samples of the in- and out-going air. Ingoing air was analyzed once every $15 \mathrm{~min}$ and out-going air every $5 \mathrm{~min}$. Relative humidity was kept between 53 and 55\%. Physical activity was monitored by means of a radar system, based on the Doppler principle. ${ }^{15}$ Twenty-four hour urine samples were collected in containers with $10 \mathrm{~mL} \mathrm{H}_{2} \mathrm{SO}_{4}$ to prevent nitrogen loss by evaporation. Total daily nitrogen excretion was calculated with $24 \mathrm{~h}$ urine nitrogen concentration, which was measured with a nitrogen analyzer (CHN-O-Rapid; Heraeus).

TDEE was calculated over $24 \mathrm{~h}$ intervals from 08.00 to 08.00 . SMR is defined to be the lowest energy expenditure at night (measured over three consecutive hours). The respiratory quotient (RQ) is the quotient of $\mathrm{CO}_{2}$ production and $\mathrm{O}_{2}$ consumption.

2.2.2. Body Composition. Whole body density was determined in fasted state by hydrodensitometry with simultaneous assessment of the lung volume using the helium dilution technique. Body weight was measured using a digital balance with an accuracy of $0.001 \mathrm{~kg}$ (ID1 plus, Mettler Toledo). Under water, body weight was measured using a digital balance with an accuracy of $0.01 \mathrm{~kg}$ (E1200, Sauter). Lung volume was measured by use of a spirometer (Volugraph 2000, Mijnhardt). \%BF (percent body fat) was calculated using the equation of Siri. $^{21}$ 
2.3. Proteomic Procedures. 2.3.1. Sample Preparation. Frozen muscle biopsies were weighed and subsequently ground using a nitrogen cooled mortar. Ground material was dissolved in $20 \mu \mathrm{L}$ Classical Lysis Buffer (CLB) (8 M Urea, 2\% Chaps, and $65 \mathrm{mM}$ DTT) per mg of muscle tissue, mixed carefully to avoid foaming for $5 \mathrm{~min}$ and centrifuged at $20000 \times \mathrm{g}$ for $30 \mathrm{~min}$ at $20{ }^{\circ} \mathrm{C}$. The supernatant was carefully collected and aliquots were stored at $-80^{\circ} \mathrm{C}$. Protein concentration was determined using a Bradford assay (BioRad Laboratories) in the presence of $8 \mathrm{M}$ urea, $2 \%$ Chaps, and $65 \mathrm{mM}$ DTT. Protein concentrations ranged from 1.2 to $6.5 \mu \mathrm{g}$ protein per $\mu \mathrm{L}$ CLB.

2.3.2. 2-D Gel Electrophoresis. One-hundred micrograms of total protein were loaded for isoelectric focusing (IEF; first dimension), which was performed on an IPG-PHOR electrophoresis unit (Amersham Biosciences) at $20^{\circ} \mathrm{C}$. Samples were further diluted in CLB to a final volume of $450 \mu \mathrm{L}$, containing $0.5 \%(\mathrm{v} / \mathrm{v})$ IPG buffer $\mathrm{pH} 3-10$ Linear and loaded onto the Immobiline Dry Strips (pH 3-10 Linear, 24 cm long, Amersham Biosciences). IEF was performed using the following program: $50 \mathrm{~V}$ for $12 \mathrm{~h}, 100 \mathrm{~V}$ for $1 \mathrm{~h}, 500 \mathrm{~V}$ for $1 \mathrm{~h}, 1000 \mathrm{~V}$ for $1 \mathrm{~h}$, $1000-8000 \mathrm{~V}$ for $2 \mathrm{~h}$, and a final step of $8000 \mathrm{~V}$ for $40000 \mathrm{~V} \cdot \mathrm{h}$. After IEF, the IPG strips were equilibrated for $15 \mathrm{~min}$ in equilibration buffer (50 mM Tris- $\mathrm{HCl}, \mathrm{pH} 6.8,6 \mathrm{M}$ urea, 30\% (v/v) glycerol, $2 \%(\mathrm{w} / \mathrm{v})$ SDS) with $1 \%(\mathrm{w} / \mathrm{v})$ DTT and $15 \mathrm{~min}$ in equilibration buffer with $2.5 \%(\mathrm{w} / \mathrm{v})$ iodoacetamide. After equilibration of the strips, they were placed onto home-cast $12 \%$ SDS-polyacrylamide gels and run for $6 \mathrm{~h}$ at a constant voltage of $200 \mathrm{~V}$ for separation in the second dimension. The three conditions of each subject were run simultaneously using a Protean Dodeca Cell electrophoresis chamber (BioRad Laboratories) to reduce technical variability. The running buffer contained $25 \mathrm{mM}$ Tris, $192 \mathrm{mM}$ glycine, and 0.1\% SDS (pH 8.3). The gels were stained with Flamingo Fluorescent Gel Stain (BioRad Laboratories) according to the manufacturer's protocol. The proteins were visualized by gel scanning with a Molecular Imager FX (BioRad Laboratories) using a resolution of $1344 \times$ 1058 pixels (56 pixels per $\mathrm{cm}$ ). Additional preparative gels were made with a higher protein load $(500 \mu \mathrm{g})$ to increase success rate of protein identification by MS/MS.

2.3.3. Image Analysis and Spot Selection. Examination of $2 \mathrm{D}$ gels was performed using the specialized image analysis software PDQuest 8.0 (BioRad Laboratories). Spots were detected and matched automatically. All spots were checked visually to correct errors. Spots that were visible on gels of more than 4 subjects were added to the reference gel and used for the analyses. Data were normalized with respect to all valid spots (all spots that have been matched to the reference gel). Spot densities were exported to the SPSS package to perform statistical analyses. Protein intensities of individual subjects were compared between interventions and baseline (overfeeding-baseline and mild cold exposure-baseline) using the nonparametric paired Wilcoxon Signed Rank test. All significant $(p<0.05)$ and borderline significant $(0.05<p<0.10)$ up- or down-regulated spots were selected for identification. Furthermore, differences between interventions and baseline were correlated to differences in TDEE using the nonparametric Spearman correlation. Again significant and borderline significant correlated spots were selected for identification. Selected spots were excised from the preparative gels with an automated Spot Cutter (BioRad Laboratories), and are referred to as differentially expressed spots.
2.3.4. Protein Identification. The excised protein spots were digested in-gel with trypsin using a MassPREP digestion robot (Waters) as described previously. ${ }^{22}$

For MS/MS analysis, $1 \mu \mathrm{L}$ of the peptide mixture and $1 \mu \mathrm{L}$ of the matrix solution $(2.5 \mathrm{mg} / \mathrm{mL} \alpha$-cyano-4-hydroxycinnamic acid (CHCA) in $50 \%$ acetonitrile/ $0.1 \%$ trifluoroacetic acid; TFA) were spotted on a 384-well MALDI target plate. Data were collected on a MALDI-TOF/TOF mass spectrometer (4800 MALDI-TOF/TOF Proteomics Analyzer, Applied Biosystems). A default calibration was applied using a six-component peptide standard spotted onto 13 different positions of the MALDI target for MS and Glu-Fibrinopeptide B $(\mathrm{m} / \mathrm{z}$ 1570.68) fragmentation for MS/MS. Typically, 1000 shots were combined for obtaining MS spectra and for MS/MS spectra 2000 shots were combined.

The GPS Explorer v3.6 software (Applied Biosystems) was employed to generate peak lists and automate MASCOT searches against the Swiss-Prot protein database for protein identification. One miss-cleavage was tolerated; carbamidomethylation was set as a fixed modification and oxidation of methionine as an optional modification. The protein charge was set at $1+$. The precursor tolerance was set to $100 \mathrm{ppm}$ and the MS/MS tolerance was set at $0.2 \mathrm{Da}$. No restrictions were made on the protein mass. Protein hits with a significant MASCOT protein score and a GPS Explorer protein score confidence index $>95 \%$ were considered identified.

2.4. Statistics. Comparisons were made using nonparametric paired Wilcoxon Signed Rank tests. Correlations were made using nonparametric Spearman correlations. Values were considered to be statistically significant if $p<0.05$. Values are reported as mean \pm standard error of mean. Statistical analyses were performed using SPSS 16.0 for Mac.

\section{Results}

3.1. Physiological Data. Physiological data of the total experimental group have been presented elsewhere. ${ }^{6}$ Only data of nine subjects whose muscle biopsies were analyzed are presented here. Mean energy expenditure of these subjects (baseline TDEE: $11.22 \pm 0.25 \mathrm{MJ} /$ day) increased significantly, both upon overfeeding (increase TDEE: $0.78 \pm 0.15 \mathrm{MJ} /$ day, $p$ $<0.01$, range $0.15-1.62 \mathrm{MJ} /$ day) and mild cold exposure (increase TDEE: $0.52 \pm 0.16 \mathrm{MJ} /$ day, $p<0.05$, range $-0.14-$ $1.18 \mathrm{MJ} /$ day). Energy balance was positive at baseline $(0.76 \pm$ $0.11 \mathrm{MJ} /$ day, $p<0.001)$ and upon overfeeding $(7.17 \pm 0.20 \mathrm{MJ} /$ day, $p<0.001)$. Upon mild cold exposure, energy balance was not different from $0(0.24 \pm 0.15 \mathrm{MJ} /$ day, NS). Mean RQ in the $2 \mathrm{~h}$ before leaving the respiration chamber (baseline RQ: 0.82 \pm 0.012 ) increased significantly after both overfeeding (increase RQ: $0.076 \pm 0.012, p<0.01$, range $0.02-0.14$ ) and mild cold exposure (increase RQ: $0.027 \pm 0.011, p<0.05$, range $-0.02-0.09$ ), indicating a larger share of glucose metabolism after both interventions.

3.2. Differentially Expressed Proteins. In total, 224 spots have been included in the analysis set (Figure 1). Of these spots, 95 (numbered spots in Figure 1) were differentially expressed, distributed over the analyses defined in section 2.3.3 (Table 2).

Out of these spots, 52 proteins were identified using MALDITOF/TOF MS (identification details, pI and molecular weight $\left(M_{\mathrm{w}}\right)$ can be found in supplemental Table 1, Supporting Information). These spots have been categorized into the following groups: metabolic; contractile; stress response; and miscellaneous proteins. One of the spots (spot 71) contained 


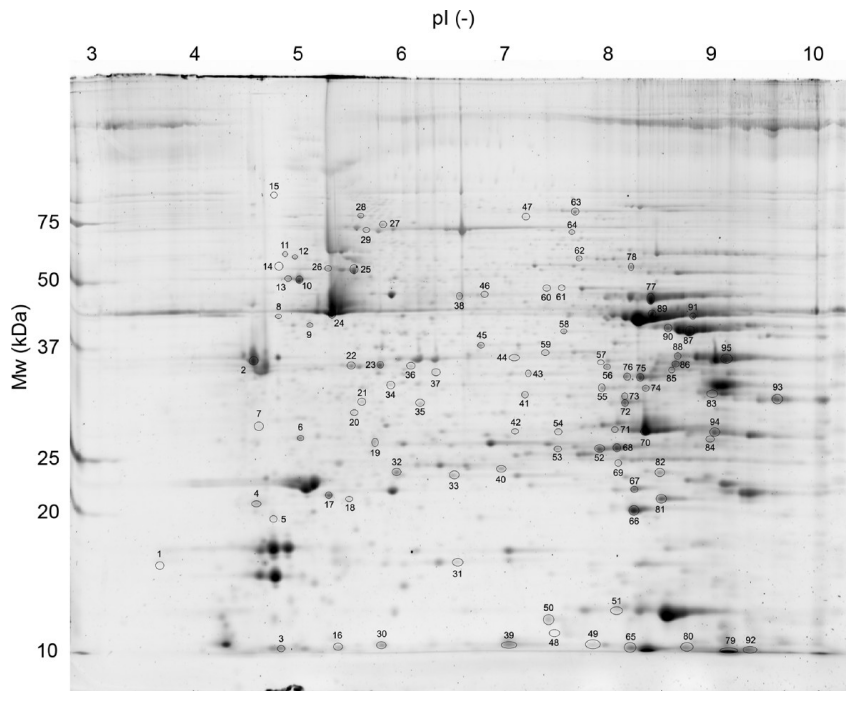

Figure 1. Representative example of a 2D gel. Numbers indicate differently expressed spots. Numbers on the gel image correspond to the spot numbers in Table 3. $M_{\mathrm{w}}$, molecular weight; $\mathrm{pl}$, isoelectric point.

Table 2. Number of Differentially Expressed Proteins

\begin{tabular}{lccccc}
\hline & overfeeding - baseline & & \multicolumn{2}{c}{ mild cold - baseline } \\
\cline { 2 - 3 } \cline { 5 - 6 } & $p<0.05$ & $0.05<p<0.10$ & & $p<0.05$ & $0.05<p<0.10$ \\
\hline $\begin{array}{l}\text { Up- or } \\
\text { down-regulated }\end{array}$ & 15 & 13 & & 15 & 28 \\
$\begin{array}{c}\Delta \text { TDEE vs } \Delta \\
\text { protein }\end{array}$ & 13 & 13 & & 10 & 10 \\
proin & & & &
\end{tabular}

two proteins (Phosphoglycerate mutase 1 and carbonic anhydrase III). Therefore, it cannot be determined directly which protein is responsible for the differential expression. An overview of the identified proteins can be found in Table 3. In supplemental Table 1 (Supporting Information), the expression data of the identified proteins can be found. The effect of mild cold exposure and overfeeding on the abundance of two representative spots and their correlation to TDEE can be seen in Figure 2. The results presented in the next subparagraphs will cover each of the protein groups mentioned above.

3.2.1. Metabolic Proteins. After overfeeding, increases in concentration of the following proteins were observed: fructosebisphosphate aldolase A, triosephosphate dehydrogenase, glyceraldehyde-3-phosphate dehydrogenase, and phosphoglycerate mutase. Only creatine kinase $\mathrm{M}$ chain showed a decrease (Figure 2, panels $\mathrm{A}-\mathrm{K}$ ). The change in creatine kinase $\mathrm{M}$ chain correlated positively to the increase in energy expenditure (Figure 2, panels $\mathrm{A}-\mathrm{K}$ ) in the overfeeding situation. Changes in triosephosphate isomerase and ATP synthase D chain correlated negatively to the increase in energy expenditure.

Upon mild cold exposure alpha enolase and ATP synthase ( $\beta$ and D chain) were up-regulated. Fructose-bisphosphate aldolase A, glyceraldehyde-3-phosphate dehydrogenase, beta enolase, pyruvate kinase, NADH-ubiquinone oxireductase, and creatine kinase ( $\mathrm{M}$ chain and sarcomeric mitochondrial) were down-regulated. Furthermore, triosephosphate isomerase, phosphoglycerate kinase 1, phosphoglycerate mutase 2, pyruvate dehydrogenase El, acyl-CoA dehydrogenase, fatty acid-binding protein, malate dehydrogenase, ATP synthase $\beta$ chain (Figure 2 , panels $\mathrm{L}-\mathrm{V}$ ), and creatine kinase sarcomeric mitochondrial correlated positively to the increase in energy expenditure (see Table 3, section A).
Fructose-bisphosphate aldolase A, triosephosphate isomerase, glyceraldehyde-3-phosphate dehydrogenase, phosphoglycerate kinase, phosphoglycerate mutase, alpha enolase, beta enolase, pyruvate kinase, pyruvate dehydrogenase, and malate dehydrogenase belong to the glycolytic/gluconeogenetic pathway, as indicated in Figure $3^{23}$ (all enzyme-clarifications without reference can be found in Alberts et al.). NADH-ubiquinone oxireductase is one of the important subunits of NADH dehydrogenase, complex I of the electron transport chain. ATP syntase $\beta$ and D chain are subunits of the ATP syntase complex (complex V) in the electron transport chain. Creatine kinase catalyzes the transfer of phosphate between ATP and creatine phosphate, enabling more flexibility in the storage of ATP in the cell. Acyl-CoA dehydrogenase (short chain specific) catalyzes the first step of beta-oxidation of short chain fatty acids, and forms therefore an important step in fatty acid oxidation. Fatty acid binding protein is associated with the uptake of fatty acids and their transport toward mitochondrial beta-oxidation. Fatty acid binding protein deficiency is associated with a switch from fatty acid to glucose substrates and accelerated fatigue. ${ }^{24}$

Because glycolysis is associated with RQ, differences in glycolysis protein concentrations have been correlated to differences in RQ. After overfeeding, differences in glyceraldehyde-3-phosphate dehydrogenase (spot 75, $r=0.753, p=0.019$ and spot 76, $r=0.795, p=0.01$ ) and pyruvate kinase (spot 78, $r=0.77, p=0.015$ ) showed positive correlations to differences in RQ. After mild cold exposure, the change in glyceraldehyde3 -phosphate dehydrogenase (spot 86, $r=0.675, p=0.046$ ) correlated positively to the differences in RQ.

3.2.2. Contractile Proteins. Upon overfeeding, troponin $T$ (fast muscle), actin, and desmin were up-regulated. Changes in troponin $\mathrm{C}$, troponin $\mathrm{T}$, and tropomyosin beta chain expression correlated negatively to the change in energy expenditure after overfeeding; the major isoform of actin (spot 24) also had a negative correlation, while spot 9 , probably a low abundance isoform, had a positive correlation.

Upon mild cold exposure, the fast skeletal muscle isoform of troponin T was up-regulated, while the slow skeletal muscle isoform was down-regulated. Changes in troponin $\mathrm{T}$ and desmin expression correlated positively to the change in energy expenditure after cold exposure (see Table 3, section B).

Actin, troponin, and tropomyosin constitute the thin filament of the sarcomeres. Desmin, which can be found near the Z-band in sarcomeres, is linked to several processes in the organization of the cell; among others it can direct mitochondria to regions of high energy demand in the cell. ${ }^{25}$

3.2.3. Stress Response Proteins. Overfeeding induced a rise in glutathione S-transferase P. The change in alpha Crystallin $B$ chain, superoxide dismutase, glutathione S-transferase $\mathrm{P}$ and carbonic anhydrase after overfeeding correlated negatively to the change in energy expenditure.

Mild cold exposure induced an increase in stress-70 protein and a decrease in heat shock cognate $71 \mathrm{kDa}$ protein and alpha Crystallin B chain (see Table 3, section C).

Heat shock cognate $71 \mathrm{kDa}$ and Stress-70 protein are part of the heat shock protein 70 family. They protect the process of protein assembly and folding in a stressed cell. ${ }^{26}$ Alpha Crystallin B chain also is a heat shock protein, it acts as a cellular chaperone to prevent aggregation of proteins after heat shock. Superoxide dismutase, glutathione S-transferase P, and carbonic anhydrase III are antioxidants, protecting cells for oxidative damage. Glutathione S-transferase also functions in the metabolism of xenobiotics. 
Table 3. Identified Proteins

\begin{tabular}{|c|c|c|c|c|c|c|c|c|c|c|c|c|c|c|}
\hline \multirow{2}{*}{ spot } & \multirow{2}{*}{ protein name } & \multirow{2}{*}{$\begin{array}{l}\text { accession } \\
\text { number }^{a}\end{array}$} & \multicolumn{6}{|c|}{ difference } & \multicolumn{6}{|c|}{ correlation } \\
\hline & & & \multicolumn{3}{|c|}{$\begin{array}{l}\text { overfeeding vs } \\
\text { baseline }\end{array}$} & \multicolumn{3}{|c|}{$\begin{array}{l}\text { mild cold vs } \\
\text { baseline }\end{array}$} & \multicolumn{3}{|c|}{$\begin{array}{l}\text { overfeeding: } \Delta \\
\text { protein vs } \Delta \text { TDEE }\end{array}$} & \multicolumn{3}{|c|}{$\begin{array}{l}\text { mild cold: } \Delta \text { protein } \\
\text { vs } \Delta T \text { DEE }\end{array}$} \\
\hline \multicolumn{15}{|c|}{ (A) Metabolic } \\
\hline 87 & Fructose-bisphosphate aldolase A & P04075 & & & & $\downarrow$ & 0.70 & 0.066 & & & & & & \\
\hline 90 & Fructose-bisphosphate aldolase A & P04075 & $\uparrow$ & 1.22 & 0.038 & & & & & & & & & \\
\hline 68 & Triosephosphate isomerase & P60174 & & & & & & & - & 0.60 & 0.088 & & & \\
\hline 75 & Glyceraldehyde-3-phosphate dehydrogenase & P04406 & & & & $\downarrow$ & 0.61 & 0.028 & & & & & & \\
\hline 76 & Glyceraldehyde-3-phosphate dehydrogenase & P04406 & & & & $\downarrow$ & 0.62 & 0.051 & & & & & & \\
\hline 86 & Glyceraldehyde-3-phosphate dehydrogenase & P04406 & & & & $\downarrow$ & 0.69 & 0.051 & & & & & & \\
\hline 95 & Glyceraldehyde-3-phosphate dehydrogenase & P04406 & $\uparrow$ & 1.22 & 0.086 & & & & & & & & & \\
\hline 91 & Phosphoglycerate kinase 1 & P00558 & & & & & & & & & & + & 0.63 & 0.067 \\
\hline 71 & Phosphoglycerate mutase 1 & P18669 & $\uparrow$ & 3.41 & 0.043 & & & & & & & & & \\
\hline 23 & $\begin{array}{l}\text { Pyruvate dehydrogenase E1 component beta } \\
\text { subunit, mitochondrial subunit }\end{array}$ & P11177 & & & & & & & & & & + & 0.58 & 0.099 \\
\hline 56 & Malate dehydrogenase, cytoplasmic & P40925 & & & & & & & & & & + & 0.60 & 0.088 \\
\hline 84 & Malate dehydrogenase, cytoplasmic & P40925 & & & & & & & & & & + & 0.81 & 0.008 \\
\hline 28 & NADH-ubiquinone oxireductase & P28331 & & & & $\downarrow$ & 0.53 & 0.066 & & & & & & \\
\hline 10 & $\begin{array}{l}\text { ATP synthase beta chain, mitochondrial } \\
\text { precursor }\end{array}$ & P06576 & & & & & & & & & & + & 0.82 & 0.007 \\
\hline 13 & $\begin{array}{l}\text { ATP synthase beta chain, mitochondrial } \\
\text { precursor }\end{array}$ & P06576 & & & & $\uparrow$ & 1.35 & 0.051 & & & & + & 0.85 & 0.004 \\
\hline 17 & ATP synthase D-chain, mitochondrial & O75947 & & & & $\uparrow$ & 1.77 & 0.021 & - & 0.60 & 0.088 & & & \\
\hline 72 & Creatine kinase, $\mathrm{M}$ chain & P06732 & $\downarrow$ & 0.59 & 0.038 & & & & + & 0.68 & 0.042 & & & \\
\hline 73 & Creatine kinase, $M$ chain & P06732 & & & & $\downarrow$ & 0.13 & 0.043 & & & & & & \\
\hline 89 & Creatine kinase, Sarcomeric mitochondrial & P17540 & & & & $\downarrow$ & 0.73 & 0.086 & & & & + & 0.67 & 0.050 \\
\hline \multicolumn{15}{|c|}{ (B) Contractile } \\
\hline 2 & Tropomyosin beta chain & P07951 & & & & & & & - & 0.65 & 0.058 & & & \\
\hline 9 & Actin, alpha skeletal muscle (Alpha-actin 1) & P68133 & & & & & & & + & 0.70 & 0.036 & & & \\
\hline 19 & Actin, alpha skeletal muscle (Alpha-actin 1) & P68133 & $\uparrow$ & 5.79 & 0.018 & & & & & & & & & \\
\hline 24 & Actin, alpha skeletal muscle (Alpha-actin 1) & P68133 & & & & & & & - & 0.58 & 0.099 & & & \\
\hline 25 & Desmin & P17661 & & & & & & & & & & + & 0.58 & 0.099 \\
\hline 26 & Desmin & P17661 & $\uparrow$ & 1.33 & 0.021 & & & & & & & & & \\
\hline \multicolumn{15}{|c|}{ (C) Stress response } \\
\hline 8 & Heat shock cognate $71 \mathrm{kDa}$ protein & $\mathrm{P} 11142$ & & & & $\downarrow$ & 0.48 & 0.050 & & & & & & \\
\hline 66 & Alpha Crystallin B chain & P02511 & & & & $\downarrow$ & 0.75 & 0.066 & - & 0.70 & 0.036 & & & \\
\hline 27 & $\begin{array}{l}\text { Stress-70 protein, mitochondrial precursor } \\
(75 \mathrm{kDa} \text { glucose regulated protein) }\end{array}$ & P38646 & & & & $\uparrow$ & 2.52 & 0.038 & & & & & & \\
\hline 67 & $\begin{array}{l}\text { Superoxide dismutase, mitochondrial } \\
\text { precursor }\end{array}$ & P04179 & & & & & & & - & 0.70 & 0.036 & & & \\
\hline 32 & Glutathione S-transferase P & P09211 & $\uparrow$ & 1.58 & 0.066 & & & & - & 0.78 & 0.013 & & & \\
\hline 70 & Carbonic anhydrase III & P07451 & & & & & & & - & 0.60 & 0.088 & & & \\
\hline 71 & Carbonic anhydrase III & P07451 & $\uparrow$ & 3.41 & 0.043 & & & & & & & & & \\
\hline \multicolumn{15}{|c|}{ (D) Miscellaneous } \\
\hline 11 & $\begin{array}{l}\text { Alpha-1-antitrypsin precursor (Alpha-1 } \\
\text { protease inhibitor) }\end{array}$ & P01009 & & & & & & & + & 0.58 & 0.099 & & & \\
\hline 12 & $\begin{array}{l}\text { Alpha-1-antitrypsin precursor (Alpha-1 } \\
\text { protease inhibitor) }\end{array}$ & P01009 & & & & $\uparrow$ & 1.39 & 0.051 & + & 0.67 & 0.050 & & & \\
\hline 55 & Esterase D & P10768 & & & & & & & - & 0.65 & 0.058 & & & \\
\hline 63 & Serotransferrin precursor & P02787 & $\downarrow$ & 0.75 & 0.028 & & & & & & & & & \\
\hline 46 & Serum albumin precursor & P02768 & $\downarrow$ & 0.53 & 0.066 & $\downarrow$ & 0.47 & 0.036 & & & & & & \\
\hline 65 & Hemoglobin beta chain & P68871 & & & & $\uparrow$ & 1.81 & 0.086 & & & & & & \\
\hline
\end{tabular}

${ }^{a}$ UniprotKB database. ${ }^{b} \mathrm{O} / \mathrm{B}$ and $\mathrm{C} / \mathrm{B}$ : fold change after intervention (spot density intervention/spot density baseline). O, overfeeding; $\mathrm{B}$, baseline; C, cold exposure. ${ }^{c} \mathrm{p}$ : p-value for the paired nonparametric Wilcoxon signed rank test, intervention minus baseline. ${ }^{d}$ r: correlation coefficient for the nonparametric Spearman correlation, spot intensity intervention minus baseline correlated to TDEE intervention minus baseline. ${ }^{e}$ p: $p^{2}$-value for the nonparametric Spearman correlation, spot intensity intervention minus baseline correlated to TDEE intervention minus baseline. 


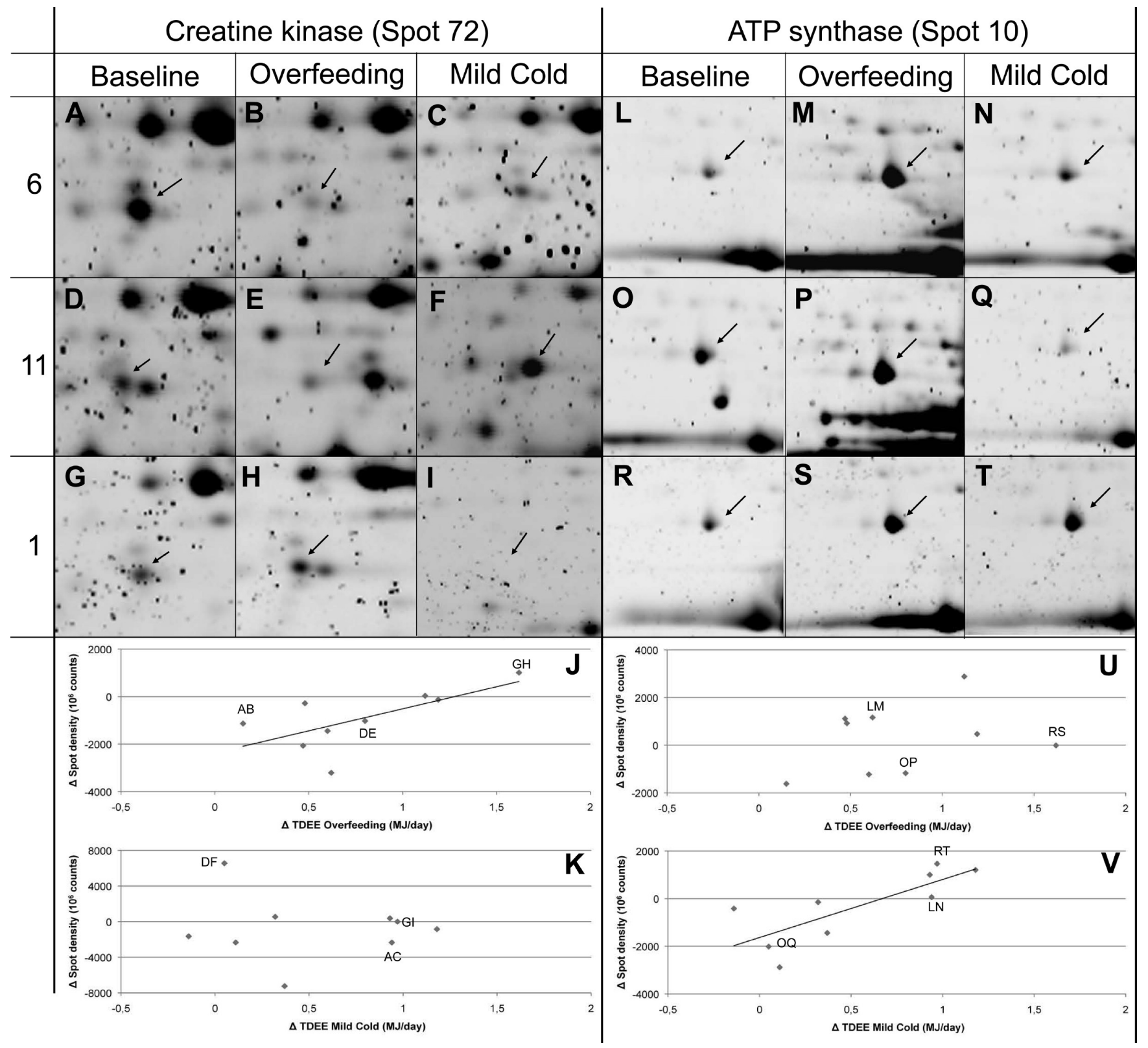

Figure 2. Relation between spot intensity and overfeeding and mild cold exposure. This figure depicts the individual spots of two of the identified proteins (creatine kinase and ATP synthase) for three of the subjects (panels A-I and L-T). Furthermore, the relation of the change in individual spot intensities with the change in energy expenditure of all subjects is plotted in panels $\mathrm{J}, \mathrm{K}, \mathrm{U}$, and $\mathrm{V}$. If a significant relation existed, a regression line has been drawn in these figures (panels $\mathrm{J}$ and V). One spot (spot 72, creatine kinase) has on group level a down-regulation and a positive correlation to the change in TDEE upon overfeeding; the other spot (spot 10, ATP synthase beta chain) has a positive correlation to the change in TDEE upon cold exposure. Panels $A, B$, and $C$ depict creatine kinase in subject 6, where the intensity is larger in the baseline situation than in the overfeeding situation (mark $A B$ in panel J). Panels $D$, $E$, and $\mathrm{F}$ depict spot creatine kinase in subject 11, where the intensity is only marginally smaller during overfeeding (mark DE in panel $\mathrm{J}$ ). Panels $G, H$, and I depict creatine kinase in subject 1, where the intensity in the overfeeding situation is larger than in the baseline situation (mark GH in panel J). In panel J. the correlation between the difference in intensity of creatine kinase and the difference in TDEE upon overfeeding is shown. Similarly, in panel K. the differences in intensity of creatine kinase and TDEE upon mild cold exposure are shown. Panels $L, M$, and $N$ depict ATP synthase in subject 6 , where the intensity is close to equal in the baseline and the mild cold situation (mark LN in panel V). Panels $O, P$, and $Q$ depict ATP synthase in subject 11, where the intensity in the baseline situation is larger than in the mild cold situation (mark $\mathrm{OQ}$ in panel V). Panels R, S, and T depict ATP synthase in subject 1 , where the intensity in the mild cold situation is larger than in the baseline situation (mark RT in panel V). In panel V, the correlation between the difference in intensity of ATP synthase and the difference in TDEE upon cold exposure is shown. Similarly, in panel $U$, the differences in intensity of ATP synthase and TDEE upon overfeeding are shown.

3.2.4. Miscellaneous Proteins. After overfeeding, serotransferrin and serum albumin decreased. Changes in alpha-1antitrypsin correlated positively and changes in esterase D correlated negatively to the change in energy expenditure after overfeeding.
After mild cold exposure alpha-1-antitrypsin increased and serum albumin decreased, while hemoglobin beta chain increased (see Table 3, section D).

Esterase D is involved in the detoxification of formaldehyde. $^{27}$ Alpha-1-antitrypsin, serotransferrin, serum albumin, 


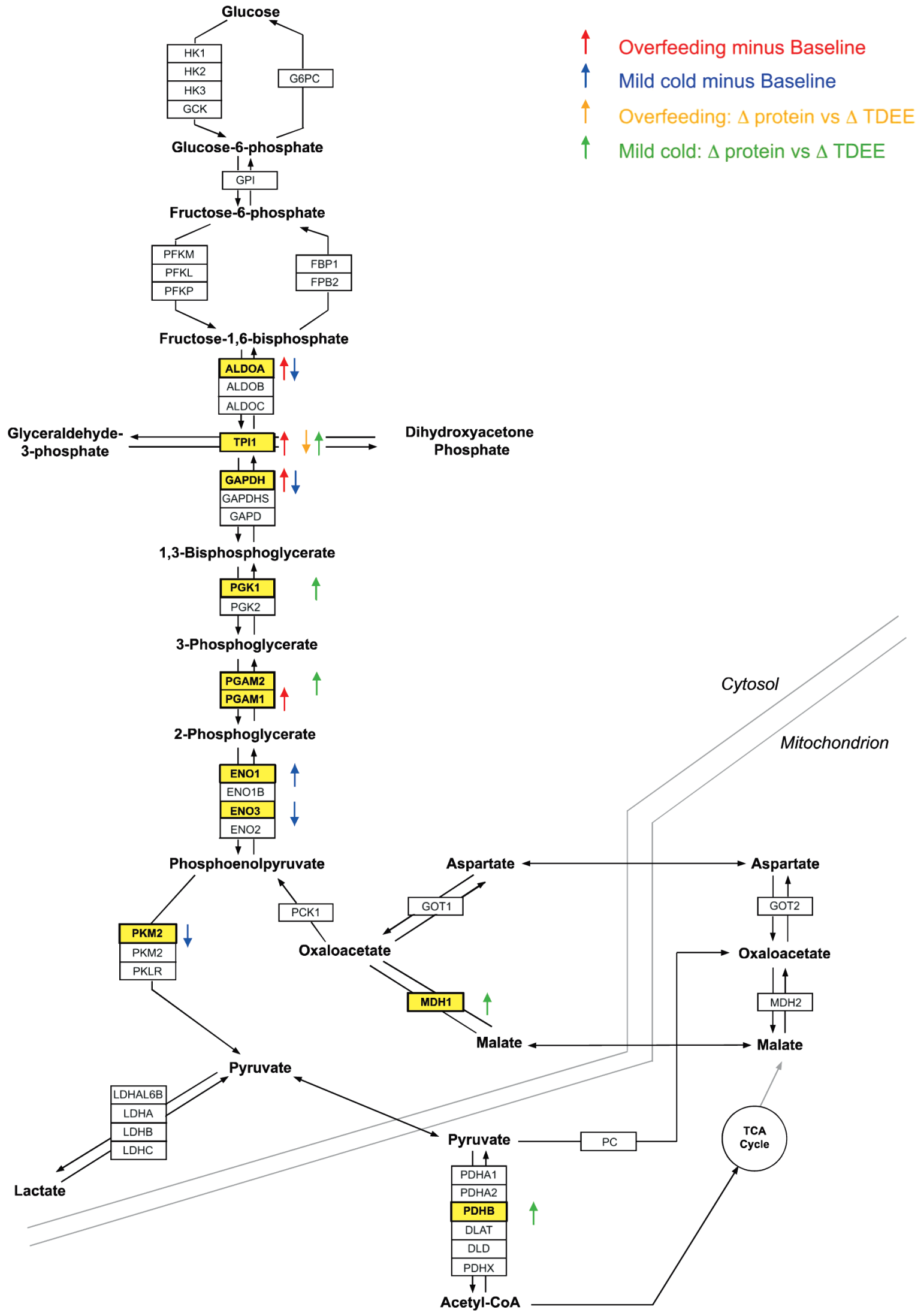

Figure 3. Glycolysis-gluconeogenesis pathway including all enzymes involved in glycolysis in humans (GenMAPP 2.0), identified proteins are marked yellow. At the right of the identified proteins, arrows indicate the direction of the changes observed (each intervention and type of analysis is indicated by a different color): the changes of protein expression upon overfeeding and mild cold exposure (respectively red and blue), and the correlation of these changes to the changes in total daily energy expenditure (respectively orange and green). Aldoa, Fructose-bisphosphate aldolase A; tpi, triosephosphate isomerase; gapdh, glyceraldehyde-3-phosphate dehydrogenase; pgk1, phosphoglycerate kinase; pgam 1 and pgam 2, phosphoglycerate mutase; eno1, alpha enolase; eno3, beta enolase; pkm2, pyruvate kinase; pdhb, pyruvate dehydrogenase; mdh1, malate dehydrogenase. 
and hemoglobin beta chain are not expressed in muscle tissue and will not be discussed here since they most likely result from blood contamination in the muscle biopsies.

\section{Discussion}

In this study, we identified proteins involved in the metabolic response to overfeeding or mild cold exposure, that is, adaptive thermogenesis. We investigated this phenomenon in the upor down-regulation of protein expression on group level. Furthermore, we investigated whether the changes in protein expression correlated to the change in energy expenditure, which is a unique approach in proteomic research. Indeed, in addition to the proteins that were up- or down-regulated, 46 proteins showed a correlation between change in spot density and change in energy expenditure. The most remarkable outcome of this study is the involvement of glycolytic pathway proteins in both cold- and overfeeding-induced adaptive thermogenesis. Additional 1D-Western blotting has been performed with antibodies against glyceraldehyde-3-phosphate dehydrogenase, alpha enolase, and pyruvate kinase isozymes $\mathrm{M} 1 / \mathrm{M} 2$, respectively, to try and verify the 2D-electrophoresis data (data not shown). However, the blotting results did not confirm the 2DE-findings. This is explained by the fact that the quantitative 2DE results are based on specific isoforms of those proteins, whereas the antibodies on 1D-Western blot do not discriminate between isoform, but visualize the total complement of a protein. Not enough material was available for $2 \mathrm{D}$-Western blotting. The current state-of-art of the proteomics technique does not enable us to easily identify the modifications of the relevant protein-isoforms. However, one of the advantages of this 2D technique above other MS based proteomics approaches is that these kinds of modifications can be detected, which impacts on the biological significance of studies like this. Some of the identified spots might result from fragments of proteins instead of intact ones, since molecular weight is lower than expected on theoretical basis (spot 45 beta enolase\}, 84 \{malate dehydrogenase\}, 72 and 73 \{creatine kinase\}, 19 \{actin\}, 8 \{heat shock cognate $71 \mathrm{kDa}$ \}, and 46 sserum albumin\}). From these truncated spots, only spot 45 and 84 are used in the discussion below. Since other isoforms of the same proteins are present with changes in the same direction, conclusions are not based solely on possibly disrupted proteins.

It should be noted that the major rate determining enzymes of glycolysis (hexokinase and PFK-1) were not detected. However, the change in relative abundance of several other glycolytic enzymes in the same direction strongly indicates regulation of the capacity of this pathway.

Several of the proteins that were up-regulated are known to differ in concentration in a broad range of proteomics studies with different interventions. ${ }^{28,29}$ Alpha enolase, heat shock cognate $71 \mathrm{kDa}$, and glutathione S-transferase are known to increase in abundance after application of different sources of stress. Therefore, these are not specifically sensitive to a change in energy expenditure but seem to react relatively independent of the kind of intervention. They will not be addressed further in this discussion.

Since the adaptive thermogenic response upon overfeeding correlated to cold-induced adaptive thermogenesis, and the sympathetic nervous system was involved in both situations, ${ }^{6}$ we hypothesized that the same cellular mechanisms might play a role during both interventions. Therefore, similar up- or down-regulations and correlations in both situations were expected. This is true for only a few proteins. One of the troponin $\mathrm{T}$ isoforms (spot 37) increased and serum albumin precursor (spot 46) decreased in both interventions. Troponin $\mathrm{T}$ is a component of the sarcomeres and functions in muscle contraction. Serum albumin is serum-specific and probably originates from blood contamination of the muscle biopsies. Therefore, it is not likely that these proteins are directly responsible for the adaptive thermogenic response.

Our expectation that detected proteins relate to both coldand overfeeding-induced adaptive thermogenesis was not confirmed. The lack of overlap in proteins involved in the reaction to overfeeding and mild cold exposure can possibly be explained by a different induction of the adaptive thermogenic response and the "side-effect" of energy expenditure that is needed, that is, heat production or substrate oxidation. Upon overfeeding adaptive thermogenesis might serve to prevent substrate (lipid and glucose) overflow by increased oxidation, consequently heat is produced. Upon cold exposure, it might serve to prevent the body from cooling by producing more heat, with as a side effect increased substrate oxidation. This different induction might trigger other pathways in the muscle tissue, although both pathways might have involvement of the sympathetic nervous system. In other words, more substrate oxidation might be required during overfeeding, which necessarily results in heat production; heat production is required during mild cold exposure, which necessarily results in an increase in substrate oxidation.

4.1. Overfeeding. Upon overfeeding, 4 out of 10 enzymes from the glycolytic pathway showed an increased abundance. This can be explained by the preference for carbohydrates as substrates, which are abundantly present due to the higher food intake. This is in line with the increased whole body carbohydrate oxidation (increased RQ). Two out of 10 glycolytic enzymes showed a change that correlated to the change in RQ, stressing the involvement of increased glucose metabolism.

Electron transport chain proteins or proteins related to uncoupling were not detected by our $2 \mathrm{D}$-gel electrophoresis, perhaps because they are membrane bound. Therefore, from this study, no conclusions can be drawn whether mitochondrial uncoupling plays a role in adaptive thermogenesis. Yet, glycolysis seems to play a role in the increase in energy expenditure, although it is not clear whether it has a causal relationship with the increase in energy expenditure upon mild cold exposure.

Nevertheless, the results cannot explain the observed interindividual variability in adaptive thermogenesis, since no correlations between the changes in protein concentrations and the changes in energy expenditure were found. Therefore, other mechanisms seem to be responsible for the large interindividual differences in adaptive thermogenesis in these subjects. Although we find negative correlations of contractile and antioxidant proteins with energy expenditure after overfeeding, it is not likely that these are responsible for the interindividual differences. If physical activity should be increased in the intervention situations of this study (which has not been observed), a positive rather than a negative correlation with contractile proteins would be expected. Lower antioxidant activity is also not associated with higher energy expenditure. Thus, no explanation for these differences can be found in this proteomics study. The interindividual differences in adaptive thermogenesis might originate from differences in activity of proteins instead of changes in concentration. Finally, it is possible that other tissues such as liver or brown adipose tissue are involved, obscuring the relation between muscle proteins and whole body energetics. 
4.2. Mild Cold Exposure. After mild cold exposure, the levels of 4 out of 10 glycolysis enzymes were decreased. In this situation, as after overfeeding, a rise in RQ was observed. However, this increase was very modest ( 0.03 units), probably below physiological relevance. No clear correlation between glycolysic proteins and RQ was found (one enzyme upregulated, one down-regulated). Despite a general decrease in glycolytic proteins levels, the changes in these proteins were positively related to changes in energy expenditure (i.e., protein levels did not change in subjects that increased energy expenditure upon cold exposure, but decreased in the subjects with an unaltered energy expenditure). Therefore, the difference in expression of these glycolytic enzymes might be responsible for the interindividual differences in adaptive thermogenesis. These results are in line with our observation that the change in mitochondrial uncoupling was positively correlated to the increase in energy expenditure, combined with a lack of differences between mean baseline mitochondrial uncoupling and mild cold exposure mitochondrial uncoupling. ${ }^{13}$

ATP synthase proteins are up-regulated upon mild cold exposure, with a positive correlation to the change in energy expenditure. This indicates an increase in ATP production, despite the lower glycolytic capacity. Therefore, an extra ATP consuming process is likely to be present. This can, for example, be calcium cycling, protein turnover or extra movement beyond detection limits. These processes might explain the increases in energy expenditure upon mild cold exposure.

This study for the first time links adaptive thermogenesis to proteins involved in glycolysis. However, more research has to be carried out to further unravel the cellular pathways behind adaptive thermogenesis. Protein activity assays could be used to investigate the differences in activity of the electron transport chain upon overfeeding or mild cold exposure. Proteomic procedures directed toward identification of membrane-bound proteins would be useful to detect whether proteins responsible for mitochondrial uncoupling might influence adaptive thermogenesis. ATP consuming futile cycles like calcium cycling and protein turnover should be investigated in relation to mild cold exposure to identify the mechanisms responsible for the downstream ATP-consumption. Furthermore, other highly metabolic tissues like BAT and liver should not be neglected.

In conclusion, after three days of overfeeding the abundance of specific isoforms of glycolytic enzymes was increased, suggesting changes in the capacity of glycolysis. Second, after three days of mild cold exposure differences in glycolytic enzyme concentrations correlate to the interindividual differences in mild cold-induced adaptive thermogenesis. Therefore, this proteomic study clearly indicates the important roles glycolytic proteins play in both cold- and overfeeding-induced adaptive thermogenesis.

Acknowledgment. We thank Paul Schoffelen and Loek Wouters for their technical assistance with indirect calorimetry measurements, Freek Bouwman and Ronny Mohren for their help with the 2D-electrophoresis and the MALDI-TOF/TOF operation, and Ping Wang for her valuable suggestions in the interpretation of the data.

Supporting Information Available: Supplemental Table 1 . This material is available free of charge via the Internet at http://pubs.acs.org.

\section{References}

(1) Lowell, B. B.; Spiegelman, B. M. Towards a molecular understanding of adaptive thermogenesis. Nature 2000, 404 (6778), 652-60.

(2) Depocas, F.; Hart, J. S.; Heroux, O. Energy metabolism of the white rat after acclimation to warm and cold environments. J. Appl. Physiol. 1957, 10 (3), 393-7.

(3) Rothwell, N. J.; Stock, M. J. A role for brown adipose tissue in dietinduced thermogenesis. Nature 1979, 281 (5726), 31-5.

(4) van Marken Lichtenbelt, W. D.; Schrauwen, P.; van De Kerckhove, S.; Westerterp-Plantenga, M. S. Individual variation in body temperature and energy expenditure in response to mild cold. Am. J. Physiol. Endocrinol. Metab. 2002, 282 (5), E1077-83.

(5) Warwick, P. M.; Busby, R. Influence of mild cold on $24 \mathrm{~h}$ energy expenditure in 'normally' clothed adults. Br. J. Nutr. 1990, 63 (3), $481-8$.

(6) Wijers, S. L. J.; Saris, W. H.; van Marken Lichtenbelt, W. D. Individual thermogenic responses to mild cold and overfeeding are closely related. J. Clin. Endocrinol. Metab. 2007, 92 (11), 4299305.

(7) Christiansen, E.; Garby, L. Prediction of body weight changes caused by changes in energy balance. Eur. J. Clin. Invest. 2002, 32 (11), 826-30.

(8) Cannon, B.; Nedergaard, J. Brown adipose tissue: function and physiological significance. Physiol. Rev. 2004, 84 (1), 277-359.

(9) Nedergaard, J.; Bengtsson, T.; Cannon, B. Unexpected evidence for active brown adipose tissue in adult humans. Am. J. Physiol. Endocrinol. Metab. 2007, 293 (2), E444-452.

(10) van Marken Lichtenbelt, W. D.; Vanhommerig, J. W.; Smulders, N. M.; Drossaerts, J. M.; Kemerink, G. J.; Bouvy, N. D.; Schrauwen, P.; Teule, G. J. Cold-activated brown adipose tissue in healthy men. N. Engl. J. Med. 2009, 360 (15), 1500-8.

(11) Simonsen, L.; Bulow, J.; Madsen, J.; Christensen, N. J. Thermogenic response to epinephrine in the forearm and abdominal subcutaneous adipose tissue. Am. J. Physiol. 1992, 263 (5 Pt 1), E850-5.

(12) Astrup, A.; Bulow, J.; Madsen, J.; Christensen, N. J. Contribution of BAT and skeletal muscle to thermogenesis induced by ephedrine in man. Am. J. Physiol. 1985, 248 (5 Pt 1), E507-15.

(13) Wijers, S. L. J.; Schrauwen, P.; Saris, W. H. M.; van Marken Lichtenbelt, W. D. Human Skeletal Muscle Mitochondrial Uncoupling Is Associated with Cold Induced Adaptive Thermogenesis. PLOS ONE 2008, 3 (3), e1777.

(14) Schrauwen, P.; Westerterp-Plantenga, M. S.; Kornips, E.; Schaart, G.; van Marken Lichtenbelt, W. D. The effect of mild cold exposure on UCP3 mRNA expression and UCP3 protein content in humans. Int. J. Obes. Relat. Metab. Disord. 2002, 26 (4), 450-7.

(15) Schoffelen, P. F.; Westerterp, K. R.; Saris, W. H.; Ten Hoor, F. A dual-respiration chamber system with automated calibration. J. Appl. Physiol. 1997, 83 (6), 2064-72.

(16) van Ooijen, A. M.; van Marken Lichtenbelt, W. D.; van Steenhoven, A. A.; Westerterp, K. R. Seasonal changes in metabolic and temperature responses to cold air in humans. Physiol. Behav. 2004, $82(2-3), 545-53$.

(17) Schrauwen, P.; van Marken Lichtenbelt, W. D.; Westerterp, K. R. Energy balance in a respiration chamber: individual adjustment of energy intake to energy expenditure. Int. J. Obes. Relat. Metab. Disord. 1997, 21 (9), 769-74.

(18) Westerterp-Plantenga, M. S.; van Marken Lichtenbelt, W. D.; Strobbe, H.; Schrauwen, P. Energy metabolism in humans at a lowered ambient temperature. Eur. J. Clin. Nutr. 2002, 56 (4), 28896.

(19) Bergstrom, J.; Hermansen, L.; Hultman, E.; Saltin, B. Diet, muscle glycogen and physical performance. Acta Physiol. Scand. 1967, 71 (2), 140-50.

(20) Weir, J. B. New methods for calculating metabolic rate with special reference to protein metabolism. J. Physiol. 1949, 109 (1-2), 1-9.

(21) Siri, W. E., Body composition from fluid spaces and density: Analysis of methods. In Techniques for measuring body composition; Bozek, J., Henschel, A., Eds.; National Academy of Sciences: Washington, DC, 1961; pp 223-4.

(22) Bouwman, F.; Suylen, D.; Renes, J.; Mariman, E. Evaluation and improving the success rate of protein identification by peptide mass fingerprinting using matrix-assisted laser desorption/ionization time-of-flight mass spectrometry. Rapid Commun. Mass Spectrom. 2005, 19 (17), 2465-8.

(23) Alberts, B.; Bray, D.; Lewis, J.; Raff, M.; Roberts, K.; Watson, J. D. Molecular Biology of The Cell, 3rd ed.; Garland Publishing: New York, 1994.

(24) Furuhashi, M.; Hotamisligil, G. S. Fatty acid-binding proteins: role in metabolic diseases and potential as drug targets. Nat. Rev. Drug Discovery 2008, 7 (6), 489-503. 
(25) Capetanaki, Y.; Bloch, R. J.; Kouloumenta, A.; Mavroidis, M.; Psarras, S. Muscle intermediate filaments and their links to membranes and membranous organelles. Exp. Cell Res. 2007, 313 (10), 2063-76.

(26) Madden, L. A.; Sandstrom, M. E.; Lovell, R. J.; McNaughton, L. Inducible heat shock protein 70 and its role in preconditioning and exercise. Amino Acids 2008, 34 (4), 511-6.

(27) Legler, P. M.; Kumaran, D.; Swaminathan, S.; Studier, F. W.; Millard, C. B. Structural characterization and reversal of the natural organophosphate resistance of a D-type esterase, Saccharomyces cerevisiae S-formylglutathione hydrolase. Biochemistry 2008, 47 (36), 9592-601.

(28) Petrak, J.; Ivanek, R.; Toman, O.; Cmejla, R.; Cmejlova, J.; Vyoral, D.; Zivny, J.; Vulpe, C. D. Deja vu in proteomics. A hit parade of repeatedly identified differentially expressed proteins. Proteomics 2008, 8 (9), 1744-9.

(29) Wang, P.; Bouwman, F. G.; Mariman, E. C. Generally detected proteins in comparative proteomics--a matter of cellular stress response. Proteomics 2009, 9 (11), 2955-66.

PR9010074 